\title{
NOTAS SOBRE LA TEORÍA DE LA COLONIALIDAD DEL PODER Y LA ESTRUCTURACIÓN DE LA SOCIEDAD EN AMÉRICA LATINA
}

\author{
Pablo QUINTERO ${ }^{1}$
}

\begin{abstract}
Resumen
La teoría de la colonialidad del poder formulada originalmente por Aníbal Quijano, a principios de los años noventa, y ampliada posteriormente por la red latinoamericana de intelectualesactivistas ligados a lo que se ha denominado "Proyecto Modernidad / Colonialidad / Descolonialidad", es una de las propuestas epistémicas más debatidas en el escenario intelectual contemporáneo en América Latina. Especialmente en la región andina, esta propuesta ha sido -y es actualmente- central en el proceso de emergencia de nuevas perspectivas críticas e ideas radicales, no sólo en el campo académico, sino fundamentalmente junto al accionar epistémico y político de los diferentes movimientos sociales. En este trabajo realizamos una revisión de los núcleos fundamentales de esta teoría, centrándonos en las elaboraciones del propio Aníbal Quijano. Introducimos los principales componentes conceptuales de la colonialidad del poder, para luego inscribir la potencialidad explicativa que contienen estos elementos teóricos en la comprensión de la estructuración de las sociedades y los Estados-nación en América Latina.
\end{abstract}

Palabras clave: Poder, Colonialidad, Sociedad, América Latina.

\begin{abstract}
The theory of the coloniality of power by Anibal Quijano, was originally formulated in the 90s, and subsequently extended by the Latin American network of intellectuals-activists linked to has been called "Project Modernity / Coloniality / Decoloniality", is a of the proposals epistemic most debated in the contemporary intellectual scene in Latin America. Especially in the Andean region, this proposal has been central in the process of emergence of new critical perspectives and radical ideas, not only in the academic field, but mainly along the epistemic and political actions of different social movements. This paper is a review of the fundamental core of this theory, focusing on the working of Anibal Quijano. Here are introduced the main conceptual components of the coloniality of power, and its potential explanatory of these theoretical elements in understanding the structure of societies and nation states in Latin America.
\end{abstract}

Keywords: Power, Coloniality, Social Structure, Latin America.

Résumé: La théorie de la colonialité du pouvoir, originalement formulée par Aníbal Quijano, au debut des années '90, et amplifiée plus tard par le réseau latinoaméricain d'intellectuelsactivistes liés au "Projet Modernité / Colonialité / Décolonialité", est une des propositions épistémiques plus débattues dans la scène intellectuelle contemporaine en Amérique Latine.

\footnotetext{
${ }^{1}$ Instituto de Ciencias Antropológicas, FFyL-UBA / CONICET pquintero@filo.uba.ar
}

Fecha de recepción del artículo: Marzo 2010

Fecha de evaluación: Mayo 2010 
Particulièrement dans la región andine, cette proposition a été -et est actuellement- centrale dans le procès d'émergence de nouvelles perspectives et idées radicales, non seulement dans le champ académique, mais surtout avec l'action épistémique et politique des différents mouvements sociaux. Dans ce travail nous réalisons une révision des points fondamentaux de cette théorie, en focalisant l'analyse sur les propres élaborations d'Aníbal Quijano. Nous introduisons les principales composantes conceptuelles de la colonialité du pouvoir, pour inscrire ensuite la potentialité explicative contenue par ces éléments théoriques dans la compréhension de la structuration des sociétés et des Etats-nations en Amérique Latine.

Mots-clé: Pouvoir, Colonialité, Structure Sociale, Amérique Latine.

\section{La Cuestión del Poder desde América Latina}

Durante todo el siglo XX los debates teóricos sobre la cuestión del poder estuvieron profundamente ceñidos a dos de las principales corrientes de la teoría social occidental y sus centros hegemónicos. Por un lado el liberalismo, que tuvo como máximo agente contemporáneo a la obra de Talcott Parsons y sus continuadores de la Escuela de Chicago en Estados Unidos. Y por otra parte, ese fragmento de la honda obra teórica de Karl Marx, que vino a denominarse materialismo histórico, representado por un cúmulo numeroso de intelectuales apegados al denominado Marxismo-Leninismo agrupados en torno a las principales academias de la extinta Unión Soviética. Ambas corrientes teóricas que fueron copiadas al calco en América Latina, fundamentaron su concepción del poder basándose ontológicamente en la escogencia privilegiada -y políticamente conveniente- de un único ámbito vital de la existencia social.

Por una parte la tradición del liberalismo, al menos desde Thomas Hobbes, ha concebido la estructuración de la sociedad como una condición determinada causalmente por la creación del contrato social como acuerdo general consensuado entre los individuos, en pos de resolver el "estado natural" de dispersión y violencia de los agrupamientos sociales. Esta concepción privilegia la conformación de un consenso de gobernabilidad, representado en la constitución de una autoridad colectiva, y recreada en las sociedades contemporáneas por el Estado. Desde este punto de vista, el poder y sus relaciones concomitantes son invisibilizados por la teoría del consenso, que define en última instancia la idea de poder como una capacidad o como un posicionamiento de carácter individual dentro de la autoridad institucional del Estado. Así en el liberalismo, el poder quedó restringido a la esfera ontológica artificial de "lo político". En la otra banda, el materialismo histórico, desnaturalizando las concepciones liberales, historizó la conformación de las diferentes formas de autoridad colectiva mostrando la importancia de las relaciones de poder dentro de dichas disposiciones. No obstante, al restringirse al análisis infraestructural caracterizado en las relaciones de producción, el materialismo histórico acotó al plano ontológico artificial de "lo económico" los demás ámbitos vitales de la existencia social, mostrándolos como objetos derivativos y determinados por el control de la fuerza de trabajo y de los recursos naturales. De esta manera, el poder en el materialismo histórico- aunque ocupa un lugar central- está particularmente referido y limitado a la dimensión de la producción.

Dentro de este constreñido escenario de debates, la cuestión del poder o fue excluida de la teoría social o quedó indefectiblemente atada a la reducción limitante de la ontología moderna. A partir de la segunda postguerra, y más precisamente con el deceso del socialismo realmente existente y su horizonte de futuro, se desplegó un fuerte proceso de penetración en el sentido común a nivel global de la teoría liberal. El poder comenzó a ser estudiado esta vez como un ejercicio básicamente discursivo y representacional. Los debates de fines de los años ochenta ya no estaban, si quiera, ceñidos a un campo de disputa utopística en el que estuvieran en pugna diferentes modelos sociales de "lo político" o de "lo económico", precisamente porque estas disputas habían perdido sentido frente a la conformación de los imaginarios hegemónicos del mercado total y del fin de la historia. Las discusiones en la teoría social comenzaron a pulular 
entonces acerca del carácter específico de esa historia planetaria actual, componiéndose el debate entre modernidad y postmodernidad. En estos debates la cuestión del poder se hizo aún más invisible al estar esencialmente abocados a la descripción de los principales aspectos de la vida social contemporánea y sus novedosas características.

En América Latina, como territorio periférico del sistema-mundo moderno, históricamente la cuestión del poder ha sido fundamentalmente visible y evidente. El pensamiento crítico latinoamericano desde sus albores se ha preguntado por la constitución y las características del poder, especialmente sobre el ejercicio del poder en nuestro continente. Precisamente hacia la cuestión del poder han apuntado los celebres debates de la intelectualidad latinoamericana en torno a los temas centrales referidos a la conquista de América, a las nacionalidades e identidades latinoamericanas, a la pregunta por el desarrollo, a la cuestión de la dependencia, y al imperialismo. A medida que se iban articulando en los centros mundiales de enunciación las discusiones entre modernidad y postmodernidad, fue conformándose en América Latina una tendencia crítica que revisitaba este debate a la luz de la cuestión del poder, más específicamente del poder colonial. De esta manera, a principios de los años noventa, a raíz de las divergentes posiciones que en esa época caracterizaban el ya citado debate, principalmente en Europa y Estados Unidos, y considerando tanto la experiencia colonial como la particular dependencia histórico-estructural de América Latina, la irrupción de Quijano (y otros intelectuales latinoamericanos que lo acompañarían) en este debate, redimensionó los términos de las discusiones hasta ese entonces producidas, al colocar en el centro de su argumentación una nueva disquisición sobre el poder y sus relaciones ${ }^{2}$. Las ideas del sociólogo peruano generaron un nuevo marco de interpretación de la modernidad a la luz de la experiencia histórica y cultural latinoamericana, erigiéndose la categoría de "colonialidad" (Quijano, 1992) como el nodo epistémico de la propuesta sobre la estructuración del poder en la modernidad.

La noción de colonialidad del poder fue el término dispuesto por Quijano para caracterizar un patrón de dominación global propio del sistema-mundo moderno/capitalista originado con el colonialismo europeo a principios del siglo XVI. En lo que sigue nos centraremos en los desarrollos teóricos de Aníbal Quijano sobre está categoría, integrándolos únicamente con las propuestas de algunos otros autores del proyecto MCD que nos parezcan imprescindibles para esclarecer y complementar algunas de las ideas desplegadas por Quijano. Para consumar lo anterior, nos permitiremos citar en varias oportunidades al autor a fin de establecer un mapeo epistémico sobre la cuestión de la colonialidad. Las notas a pie de página que aparecerán a lo largo del texto pretenden ser una guía para rastrear los umbrales de las ideas de Quijano, y asimismo para recorrer -por medio de sus escritos principales- algunas categorías conceptuales medulares de su pensamiento. Esta cartografía sólo pretende aproximar al lector a los postulados centrales de la teoría de la colonialidad del poder, pero bajo ningún concepto intenta ser una introducción y mucho menos un manual para la comprensión de dicha teoría y de sus corolarios para repensar América Latina.

Los planteamientos de Quijano y del proyecto MCD son nombrados y considerados aquí con el estatus de "teoría". Aún cuando este epítome puede resultar incompleto, pues en realidad el conjunto de reflexiones que se articulan en torno a la idea de la colonialidad del poder, representan más bien una profunda perspectiva epistémica y política que no puede ser reducida en su conjunto a la dicción de "teoría" pues abarca mucho más que esto último. No obstante, y aunque resulta más adecuado referirse a este conglomerado epistémico y político como "perspectiva", preferimos en este texto hablar atenuadamente de "teoría" al reducirnos aquí a la dimensión explicativa y sistemática de los postulados principales de Aníbal Quijano en relación a la colonialidad del poder.

${ }^{2}$ Para ver los orígenes de la inserción y participación crítica de Quijano y otros autores latinoamericanos en el debate modernidad/postmodernidad pueden verse Dussel (1994), Lander (1997) y Quijano (1990). Para una caracterización más amplia del proyecto MCD, ver Escobar (2005) y Palermo (2005). 


\section{Poder y Estructuración Social}

Para Aníbal Quijano, toda forma de existencia social que se reproduce en el largo plazo implica cinco ámbitos básicos de existencia sin los cuales no sería posible: trabajo, sexo, subjetividad/intersubjetividad, autoridad colectiva y naturaleza. La disputa continua por el control de dichos ámbitos acarrea la (re)producción de las relaciones de poder. Desde esta perspectiva, el fenómeno del poder se caracteriza por ser un tipo de relación social constituida por la co-presencia y la interactividad permanente de tres elementos: la dominación, la explotación y el conflicto. Estos tres elementos afectan a los cinco ámbitos básicos de la existencia social y son a la vez el resultado y la expresión de la disputa por el control de ellos, a saber: 1) El trabajo, sus recursos y sus productos; 2) El sexo, sus recursos y sus productos; 3) La subjetividad/intersubjetividad, sus recursos y sus productos; 4) La autoridad colectiva (o pública), sus recursos y sus productos; 5) Las relaciones con las demás formas de vida y con el resto del universo (naturaleza):

Podría decirse, en tal sentido, que el poder es una relación social de dominación, explotación y conflicto por el control de cada uno de los ámbitos de la experiencia social humana (Quijano, 2001b: 10).

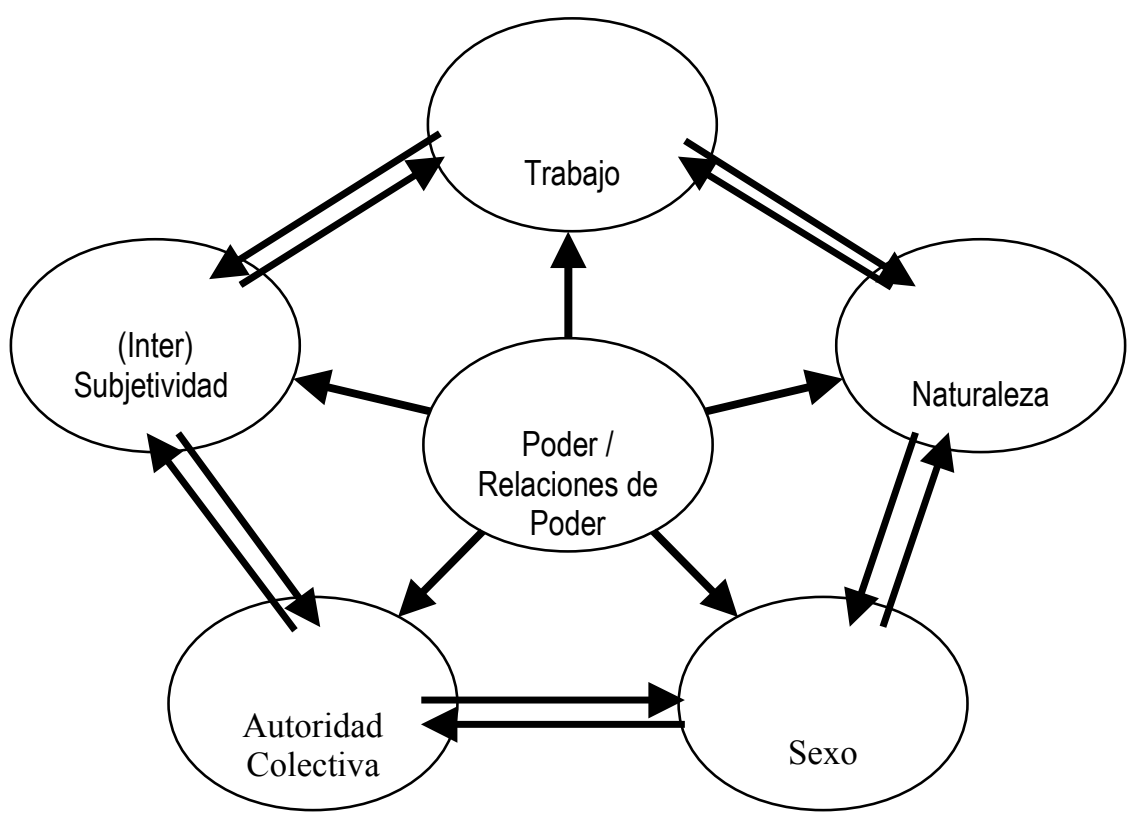

Figura 1. El poder y los ámbitos básicos de la existencia social.

En este marco propositivo, la dominación se erige como el elemento más general de las relaciones de poder y por ende como su condición básica. Dicha condición se funda en una relación asimétrica en donde algunas agrupaciones sociales ejercen el control sobre el comportamiento de otras. Aunque la dominación recae sobre todos los ámbitos de la existencia social y se establece como condición primordial para su control, son la autoridad colectiva y la subjetivad/intersubjetividad sus ámbitos centrales. Así, la imposición de la dominación por 
medio de la violencia organiza una estructura de autoridad (colectiva) al tiempo que se legitima en la subjetividad/intersubjetividad ${ }^{3}$.

La dominación del trabajo, es decir la explotación, radica precisamente en el mantenimiento de una relación de inequidad persistente, sustentada -por parte de un grupo o individuo- en la obtención constreñida del trabajo de los demás, sin retribución equivalente o compartición con ellos. La prolongación en el tiempo de la explotación, en tanto dominación del trabajo, constituye las relaciones de propiedad y las relaciones de producción. De esta forma, se instituye la dominación como la condición de posibilidad de la explotación, pero no a la inversa ${ }^{4}$. La dominación y la explotación -como elementos permanentes del fenómeno del poder- implantan necesariamente el conflicto como tercer elemento de esta triada. El objetivo del conflicto es el cambio o la destrucción de los recursos y de las instituciones configuradas y reproducidas por la dominación, aún cuando también éste se funda en la tentativa por controlar los ámbitos básicos de la existencia social ${ }^{5}$.

Con esta propuesta aún en pleno desarrollo, Quijano se refiere sucintamente al control del trabajo moldeando principalmente el manejo y manipulación del medio ambiente y de las tecnologías de sobrevivencia. Mientras que el control del sexo y de la reproducción sexual estaría articulado a la generación de placer/displacer y a la reproducción de la especie. Por otro lado, el control de la subjetividad/intersubjetividad se refiere a la producción de sentidos sociales incluidos aquí los imaginarios, las memorias históricas y las perspectivas centrales de conocimiento. El control de la autoridad colectiva remitiría a la organización social y, finalmente, el control de la naturaleza expide a la obtención de recursos y la reproducción de la vida.

\footnotetext{
${ }^{3}$ Es plausible denotar en este punto la influencia del marxismo latinoamericano de José Carlos Mariátegui (1928) en la visión que tiene Quijano sobre la dominación. Aún con más ahínco se nota la distancia entre nuestro autor y la concepción weberiana de dominación y sus subsiguientes clasificaciones tipológicas tan caras al liberalismo contemporáneo. Sobre el desarrollo de la idea de dominación, ver Quijano (2007b: 96), (2001a: 34 y ss.), (2001b: 8 y ss.), (1998: 29 y ss.), (1993: 171 y ss.), (1990: 38), (1979: XLIII y ss.), y (1975: 91 y ss.).
}

${ }^{4}$ La propuesta conceptual de Quijano sobre la explotación como elemento del poder social, se refiere a una relación desigual tanto desde el punto de vista económico como ético. En ambos puntos de vista es posible denotar una veta de la última etapa del pensamiento de Karl Marx, (principalmente en el primer tomo de El Capital). No obstante, para Quijano -a contramano del materialismo histórico- la explotación no es la única forma de dominación existente. Para rastrear esta concepción sobre la explotación puede verse, Quijano (2004: 75 y ss.), (2001a: 35 y ss.), (2001b: 8), (2000a: 204 y ss.), y (2000b: 74 y ss.).

${ }^{5}$ La conceptualización del conflicto que hace Quijano se aleja de la versión de la teoría sociológica liberal tradicional, que suele considerar al contrato social, al consenso o a la integración como la condición primordial de la existencia social, visibilizando en líneas generales al conflicto como un estado social perjudicial o atípico. Probablemente el influjo más patente en el pensamiento de Quijano sobre el asunto del conflicto provenga de Charles Wright Mills (1961) y su consideración del conflicto social, no como un desajuste o desorden, sino más bien como un elemento concomitante de la sociedad que responde directamente a lo que él mismo denominó como "la organización del poder". Para seguir la pista de los planteamientos sobre el conflicto, ver Quijano (2007b: 96), (2001a: 25 y ss.), (2001b: 10), (1998: 27 y ss.), y (1975: 99 y ss.). 


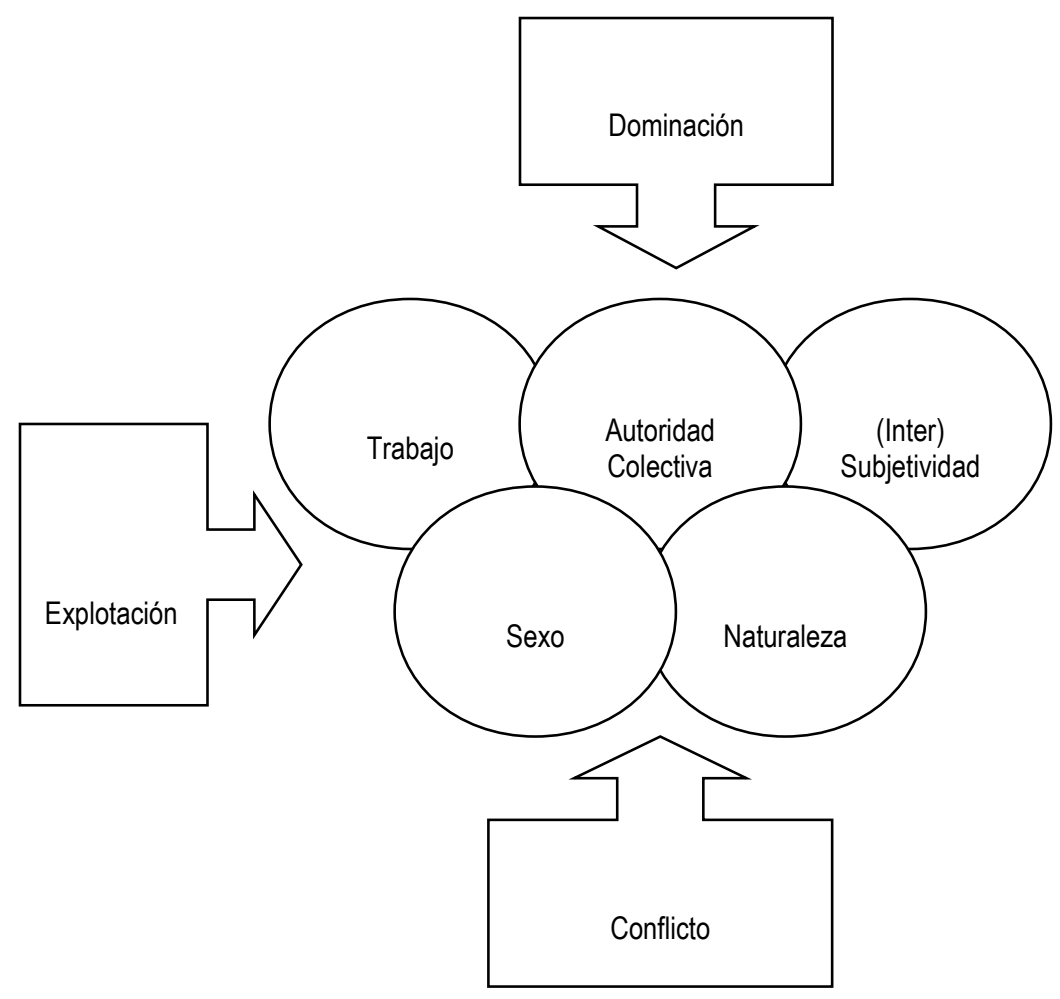

Figura 2. La tríada de elementos del poder y los ámbitos básicos de la existencia social.

Como se ve, cada uno de estos cinco ámbitos básicos de la existencia social son afectados por la tríada de elementos que constituyen el poder. Por ende, las formas de existencia social, no pueden existir u operar separadas o de manera independiente. Asimismo, las relaciones de poder que se constituyen en la disputa por el control de dichas áreas de la existencia social, tampoco pueden existir $\mathrm{u}$ operar las unas sin las otras, precisamente porque forman un complejo estructural y una totalidad histórica ${ }^{6}$. Pero en esa misma medida, las relaciones de poder en cada ámbito se comportan con ritmos y maneras diferentes, siempre dentro de la estructura conjunta. Estos diferentes ritmos y maneras que se articulan en cada ámbito así como en la estructura conjunta, dependen directamente de las conductas concretas de los colectivos humanos, lo cual le otorga al complejo estructural un carácter necesariamente histórico, heterogéneo y discontinuo.

Desde esta perspectiva, las relaciones sociales son formaciones configuradas por las acciones de los sujetos y de las agrupaciones sociales en el devenir de sus disputas y conflictos. Cuando estas acciones se reproducen tendiendo a la permanencia producen pautas o modelos de comportamiento. Dichos modelos de conducta mantenidos en el largo plazo conllevan a la conformación de instituciones sociales que posteriormente darán forma a las acciones y

${ }^{6}$ La idea de totalidad tal como la expresa Quijano, no representa la teorización de una estructura homogénea, cerrada o sistémica-orgánica de corte estructural-funcionalista. Muy por el contrario, la noción de totalidad representa aquí una estructura abierta y heterogénea tanto en su comportamiento como en sus determinaciones. A lo que apunta Quijano con la idea de totalidad, es hacia la articulación de historias específicas, heterogéneas y discontinuas (historias locales) en una nueva estructura global de poder social que se constituye con la modernidad/colonialidad. Para esto puede consultarse Quijano (2007b: 98 y ss.) y (2001b: 7 y ss.). 
conductas de los sujetos. Según Quijano, estos patrones de comportamiento y sus respectivas instituciones, podemos denominarlos como estructuras, es decir, directrices medulares para la reproducción de las formas de comportamiento de los sujetos y agrupaciones sociales que se gestan, a su vez, dentro de ciertos modelos generales configurados por las instituciones sociales (Quijano, 2001b:10).

\begin{abstract}
Lo interesante aquí, es que la historia conocida, es la disputa por el control de todos y cada uno de aquellos ámbitos de la existencia social y el poder resultante -relaciones de dominación / explotación / conflicto- lo que da configuración al comportamiento social de las gentes es decir las "estructuras". Y dentro de tales "estructuras", las conductas estructuradas de las gentes, es decir los "procesos", se reiteran hasta que las tensiones, las contradicciones y el conflicto las hace estallar y vuelve el viejo ciclo de disputas y de victorias y derrotas y de reproducción de las conductas impuestas, incluidas las formas de conflicto. En otros términos, puesto que en todas las sociedades de las cuales tenemos información el poder ha estado presente, no es arbitrario afirmar que es eso -el poder- lo que articula las diversas y dispersas experiencias sociales en una estructura conjunta que reconocemos con el nombre de sociedad (Quijano, 2001b: 11).
\end{abstract}

Por lo tanto, las relaciones sociales no son de ninguna manera el producto consecuente de un acuerdo atemporal, y por ende espontáneo o natural, entre los individuos de una sociedad, tal como se afirma en el liberalismo. De la misma forma, las relaciones sociales no son tampoco el resultado de factores y agentes universales, externos e independientes a la sociedad, como propugna el materialismo histórico. En consecuencia, las relaciones sociales y los patrones de poder que configuran a éstas, son necesariamente específicos e históricos, pues se desenvuelven en cronotopos particulares.

\title{
Colonialidad del Poder y Estructuración Social en la Modernidad
}

El actual patrón específico e histórico de poder, designado por Aníbal Quijano con el epíteto de colonialidad, se compone a partir de la asociación estructural de dos ejes centrales que fueron constituyéndose a partir de la conquista de América entre fines del siglo XV y principios del siglo XVI. En palabras de Quijano:

La colonialidad del poder es uno de los elementos constitutivos del patrón global de poder capitalista. Se funda en la imposición de una clasificación racial/étnica de la población del mundo como piedra angular de dicho patrón de poder, y opera en cada uno de los planos, ámbitos y dimensiones, materiales y subjetivas de la existencia cotidiana y a escala social. Se origina y mundializa a partir de América. Con la constitución de América (Latina), en el mismo momento y en el mismo movimiento histórico, el emergente poder capitalista se hace mundial, sus centros hegemónicos se localizan en las zonas situadas sobre el Atlántico -que después se identificarán como Europa-, y como ejes centrales de su nuevo patrón de dominación se establecen también la colonialidad y la modernidad. En otras palabras: con América (Latina) el capitalismo se hace mundial, eurocentrado y la colonialidad y la modernidad se instalan, hasta hoy, como los ejes constitutivos de ese específico patrón de poder (Quijano, 2007b: 93-94).

El primer eje consiste en un sistema de dominación asentado en un entramado de relaciones sociales intersubjetivas, basadas en la clasificación social jerárquica de la población mundial, sostenida en la configuración y naturalización de la idea de "raza". La idea de raza como primera categoría social de la modernidad (Quijano, 1992), ha desempeñado un papel central dentro de las nuevas identidades geoculturales globales que se constituyeron con el colonialismo hispánico a principios del siglo XVI, articulándose posteriormente con otras formas de clasificación social basadas en las ideas de clase y de género/sexualidad ${ }^{7}$.

${ }^{7}$ Quijano afirma que la clasificación social basada en la idea de género es la más antigua en la historia de la humanidad, no obstante, reconoce que esta primera idea es rearticulada y supeditada a la noción de raza 
Con la formación de América se establece una categoría mental nueva, la idea de raza. Desde el inicio de la conquista, los vencedores inician una discusión históricamente fundamental para las posteriores relaciones entre las gentes de este mundo, y en especial entre europeos y no-europeos, sobre si los aborígenes de América tiene alma o no; en definitiva si tienen o no naturaleza humana. La pronta conclusión decretada desde el Papado fue que son humanos. Pero desde entonces, en las relaciones intersubjetivas y en las prácticas sociales del poder, quedó formada, de un parte, la idea de que los no-europeos tienen una estructura biológica no solamente diferente de la de los europeos; sino, sobre todo, perteneciente a un tipo o a un nivel inferior. De otra parte, la idea de que las diferentes culturas están asociadas a tales desigualdades biológicas y que no son, por lo tanto, producto de la historia de las relaciones entre las gentes y de éstas con el resto del universo. Estas ideas han configurado profunda y duraderamente todo un complejo cultural, una matriz de ideas, de imágenes, de valores, de actitudes, de prácticas sociales, que no cesa de estar implicado en las relaciones entre las gentes, inclusive cuando las relaciones políticas coloniales ya han sido canceladas. Ese complejo es lo que conocemos como racismo (Quijano, 1993: 167) ${ }^{8}$.

En el patrón de poder de la colonialidad, la idea de raza y el complejo ideológico del racismo, impregnan todos y cada uno de los ámbitos de existencia social y constituyen la más profunda y eficaz forma de dominación social, material e intersubjetiva (Quijano, 2000b). Es por ello que la posición subalterna de los pueblos sometidos por este específico e histórico patrón de dominación, será vista no como el resultado de un conflicto de poder sino como la derivación lógica de una inferioridad esencial en su naturaleza9 9

El segundo eje de la colonialidad, como actual patrón de poder, esta compuesto por un sistema de relaciones sociales materiales que se gestó en el mismo movimiento histórico de producción y de control de subjetividades que da origen a los ejercicios clasificatorios descritos en el primer eje. En este sentido, con la conquista de América, comienza a gestarse paralelamente un nuevo sistema de control del trabajo, que consiste en la articulación de todas las formas conocidas de explotación en una única estructura de producción de mercancías para el mercado mundial, alrededor de la hegemonía del capital. La categoría analítica de "capitalismo" se refiere precisamente al conjunto formado por dicha articulación estructural. Efectivamente, el capitalismo se desarrolló desintegrando a todos los antiguos patrones de control del trabajo, absorbiendo y redefiniendo todos los fragmentos estructurales anteriores que le fueran útiles. Aunque este eje del actual patrón de poder se manifiesta globalmente desde sus comienzos, no ha existido nunca de modo histórico homogéneo. Por el contrario, debido a su propio carácter, el capitalismo articula (además de diferentes formas de explotación) múltiples contextos histórico y estructuralmente heterogéneos, configurando con todos ellos un único orden mundial encarnado en el actual patrón global del control del trabajo ${ }^{10}$.

como categoría central de diferenciación social de la colonialidad (2007a: 132 y ss.). En el mismo sentido, Quijano advierte la potencia contemporánea de la idea de clase, pero recuerda que este término sólo apareció en el siglo XVIII bajo los estudios naturalistas, probablemente siendo propuesta por primera vez por Carl Linneo (Quijano, 2007b: 111 y ss.). Para un intento reciente por redimensionar el papel que juegan tanto el género como la sexualidad en la colonialidad del poder, a partir de los planteamientos de Quijano, puede verse Lugones (2008) y Palermo (2006).

${ }^{8}$ Para una revisión más completa sobre la formación histórica de la idea de raza, puede consultarse Quijano (2009: 3), (2007a: 130 y ss.), (2000a: 202 y ss.), (2000c: 37 y ss.), y (1993: 168 y ss.).

${ }^{9}$ Walter Mignolo (2003) ha caracterizado esta lógica clasificatoria bajo el apelativo de "diferencia colonial". La diferencia colonial sería así, un dispositivo producido por la colonialidad del poder, que consiste en clasificar grupos humanos o poblacionales, identificándolos con sus "faltas o excesos" de acuerdo a los patrones eurocentrados de la colonialidad, lo cual marca la distinción y la inferioridad con respecto a quien clasifica.

${ }^{10}$ Dentro de la extraordinariamente extensa literatura crítica sobre el modo de producción capitalista, las ideas de Aníbal Quijano sobre estos asuntos se han visto influenciadas principalmente por su lectura 
En el proceso de constitución histórica de América, todas las formas de control y de explotación del trabajo y de control de la producción-apropiación-distribución de productos, fueron articuladas alrededor de la relación capital salario y del mercado mundial. Quedaron incluidas, la esclavitud, la servidumbre, la pequeña producción mercantil, la reciprocidad y el salario. En tal ensamblaje, cada una de dichas formas de control del trabajo no era una mera extensión de sus antecedentes históricos. Todas eran histórica y sociológicamente nuevas. En primer lugar, porque fueron deliberadamente establecidas y organizadas para producir mercaderías para el mercado mundial. En segundo lugar, porque no existían sólo de manera simultánea en el mismo espacio/tiempo, sino todas y cada una articuladas al capital y a su mercado, y por ese medio entre sí. Configuraron así, un nuevo patrón global de control del trabajo, a su vez un elemento fundamental de un nuevo patrón de poder, del cual eran conjunta e individualmente dependientes histórico-estructuralmente. Esto es, no sólo por su lugar y función como partes subordinadas de una totalidad, sino porque sin perder sus respectivas características específicas y sin perjuicio de las discontinuidades de sus relaciones con el orden conjunto y entre ellas mismas, su movimiento histórico dependía en adelante de su pertenencia al patrón global de poder. En tercer lugar, y como consecuencia, para colmar las nuevas funciones cada una de ellas desarrolló nuevos rasgos y nuevas configuraciones histórico-estructurales (Quijano, 2000a: 204) ${ }^{11}$.

Sobre la configuración de estos dos ejes, por un lado, la producción de nuevas identidades geoculturales (indios, negros, blancos, y en otro sentido, América, Europa, Occidente, Oriente, etc.) y por otra parte, el control del trabajo a través del surgimiento de nuevas relaciones sociales materiales de producción, se conforma la colonialidad como patrón de poder global. Aunque posee un carácter global, es claro que la colonialidad del poder se ha gestado en los diferentes espacios y tiempos planetarios de forma específica y heterogénea, sufriendo además constantes transformaciones históricas pero no por eso dejando de existir como fundamento de las relaciones de dominación, explotación y conflicto ${ }^{12}$.

heterodoxa y abierta de la obra de Karl Marx, así como por el modelo de sistemas históricos propuesto y desarrollado ampliamente por Immanuel Wallerstein (1990) y por las investigaciones aún en curso de Dale Tomich (2004). La modalidad bajo la cual se articulan las diferentes formas de control y de explotación del trabajo en Quijano dista mucho de la propuesta de articulación de modos de producción al estilo del estructuralismo marxista de la escuela francesa. Quizás los clásicos estudios de Claude Meillassoux (1977) encierren alguna similitud con las ideas propugnadas en este punto por Quijano. No obstante, este último en un tono heterodoxo reconoce la existencia de relaciones socioeconómicas alternativas o al menos semi-exteriores al capitalismo (Quijano, 2004: 81), lo cual da lugar a pensar en una utopía de futuro, muy al contrario de Meillassoux donde nos encontramos ante un panorama negativista donde un capitalismo deificado domina sin excepción todas las relaciones socioeconómicas.

${ }^{11}$ Para una historización de las principales transformaciones del capitalismo en relación con la colonialidad del poder, ver Quijano (2009: 5 y ss.), (2004: 76 y ss.), (2001a: 29 y ss.), y (2000a: 204 y ss.).

${ }^{12} \mathrm{Ha}$ de notarse que el concepto de colonialidad del poder difiere de la noción de colonialismo. Colonialismo designa una relación política y económica, en la cual la soberanía de un pueblo reside en el poder de otro pueblo o nación. En contraposición a esto, la colonialidad se refiere a un patrón de poder que emergió como resultado del colonialismo moderno, pero que en lugar de estar limitado a una relación de poder entre dos pueblos o naciones, más bien se refiere a la forma como el trabajo, el conocimiento, la autoridad y las relaciones intersubjetivas se articulan entre sí a través del mercado capitalista mundial y de la diferencia colonial. Así, pues, aunque el colonialismo precede temporalmente a la colonialidad, la colonialidad, en tanto matriz de poder, sobrevive al colonialismo. 


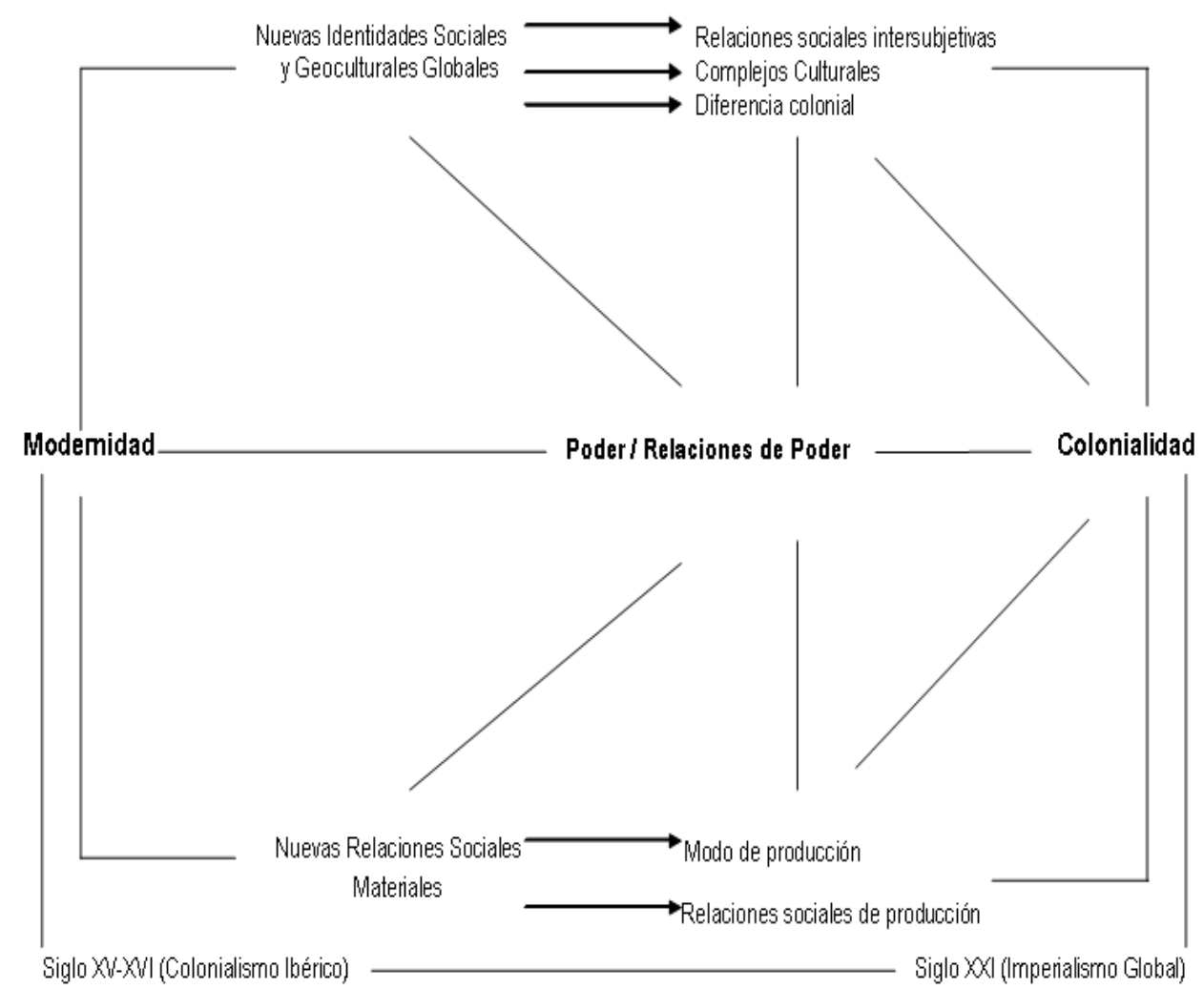

Figura 3. El proceso de estructuración de la colonialidad del poder.

De la misma forma, dentro de los ejes de la colonialidad del poder, los modos de producción y de control de la subjetividad adquieren un carácter específico supeditado a este patrón de poder. Como enunciamos, la subjetividad, es desglosada por Aníbal Quijano en tres elementos fundamentales: el imaginario social, la memoria histórica y las perspectivas de conocimiento (2002). Dentro del patrón de poder de la colonialidad estos tres elementos se expresan en el "eurocentrismo". Así denomina Quijano el modo de producción y de control de las relaciones intersubjetivas, que fue elaborado y sistematizado a mediados del siglo XVII en Europa, como parte del eurocentramiento del patrón de poder moderno/colonial. Así, el eurocentrismo está caracterizado por un imaginario social, una memoria histórica y una perspectiva de conocimiento, dependientes tanto de las exigencias del capitalismo como de la necesidad de los colonizadores de perpetuar y naturalizar su dominación. Esto obviamente, ha incluido históricamente la apropiación de los logros intelectuales e incluso tecnológicos de los colonizados. No obstante, el rasgo más potente del eurocentrismo ha sido un modo de imponer sobre los dominados un espejo distorsionante que les obligará, en adelante, a verse con los ojos del dominador, bloqueando y encubriendo la perspectiva histórica y cultural autónoma de los dominados bajo el patrón de poder actual ${ }^{13}$ :

El eurocentrismo, por lo tanto, no es la perspectiva cognitiva de los europeos exclusivamente, o sólo de los dominantes del capitalismo mundial, sino del conjunto de los educados bajo su hegemonía. Se trata de la perspectiva cognitiva producida en el largo tiempo del conjunto del mundo eurocentrado del capitalismo colonial/moderno, y que naturaliza la experiencia de las gentes en este patrón de poder. Desde el siglo XVIII, sobre todo con el Iluminismo, en el eurocentrismo se fue afirmando la mitológica idea de que Europa era preexistente a ese patrón de

${ }^{13} \mathrm{La}$ idea de eurocentrismo tal como la concibe Quijano, ha sido desarrollada acuciosa y extensamente por Enrique Dussel (2000 y 1994). Por otro lado, Fernando Coronil (2000), ha desplegado sendas nociones que historizan y complejizan la idea de eurocentrismo de Quijano y Dussel. 
poder; que ya era antes un centro mundial del capitalismo que colonizó al resto del mundo y elaboró por su cuenta y desde dentro la modernidad y la racionalidad. En este orden de ideas, Europa y los europeos eran el momento y el nivel más avanzado en el camino lineal, unidireccional y continuo de la especie. Se consolidó así, junto con esta idea, otro de los núcleos principales de la modernidad/colonialidad: Una concepción de la humanidad, según la cual la población del mundo se diferencia en inferiores y superiores, irracionales y racionales, primitivos y civilizados, tradicionales y modernos (Quijano, 2007b: 94-95).

De esta manera, al hablar de colonialidad se está denotando el patrón de poder global del sistema-mundo moderno/capitalista originado con la conquista de América, por parte del colonialismo europeo del siglo XVI (principalmente español y portugués), continuado bajo la hegemonía francesa y holandesa durante el siglo XVIII, prolongado con el imperialismo inglés en el siglo XIX, y extendido con el dominio del imperialismo norteamericano desde principios del siglo XX hasta hoy en día, a través de una larga lista de transformaciones y transmutaciones de las dimensiones subjetivas (clasificaciones sociales) y materiales (formas de control del trabajo) de este patrón. Por ende, es posible hablar de una matriz colonial del poder, en tanto que sistema ordenador y acumulativo de las relaciones sociales y de la disposición del poder, en la trama de relaciones sociales que constituye la historia de América Latina (Palermo, 2006). Ciertamente, con la independencia latinoamericana a principios del siglo XIX, se inicia un proceso de descolonización pero no de descolonialidad. Es decir, los nuevos estados-nacionales latinoamericanos logran independizarse de las potencias hegemónicas, pero la colonialidad y sus efectos fundamentales siguen operando a lo interno de los distintos países, produciéndose, con el tiempo, diferentes estructuraciones sociales, todas, no obstante, articuladas bajo el manto de la diferencia colonial y del control del trabajo por medio del capitalismo. Sin duda alguna, la colonialidad del poder es el elemento central de la estructuración de la sociedad en América Latina.

\section{Notas sobre la Estructuración de las Sociedades Latinoamericanas}

El proceso de conformación de los Estados-Nación y de las identidades nacionales que se gestó en Europa, estuvo acompañado por el desarrollo del capital como relación social, esto conllevó un proceso de clasificación social basado en la idea de clase (burguesía, sectores medios, asalariado urbano, etc.) dentro de una población étnica y racialmente homogénea, desde la perspectiva de la diferencia colonial. Este sumario trajo consigo una mercantilización de las relaciones sociales y una secularización de la subjetividad (Quijano, 2000a). Así, los derroteros de las relaciones de dominación, explotación y conflicto estuvieron articulados en torno a las dinámicas entre clases, particularmente, la conflictividad se desarrolló entre explotadores y explotados. De esta manera, las conquistas de las clases subalternizadas por el control del trabajo, permitieron la democratización de las relaciones sociales mediante la disputa por el control de la autoridad colectiva, especialmente en aquellos territorios donde se gestaron movimientos revolucionarios que permitieron destilar las relaciones de poder alrededor del control de los medios de producción. El resultado más visible de estos procesos fue la configuración de relaciones intersubjetivas de particular cuño que desarrollaron sentidos de pertenencia, por un lado materiales, ligados a unidades territoriales específicas, y por otro lado imaginarios, enlazados a la noción de patria.

Posteriormente a este proceso, la formación de los Estados-Nación y de las identidades nacionales en América Latina, estuvo caracterizada por su carácter intrínsecamente colonial. En el caso latinoamericano, a través de la imposición de la reproducción, subsumida al capitalismo, de las demás formas de explotación del trabajo, se desarrolló un modelo de clasificación racial entre blancos y las demás tipologías consideradas como inferiores. La supeditación de las relaciones sociales al colonialismo, subordinó la producción de subjetividades de las 
poblaciones dominadas a la imitación o el remedo de los modelos culturales europeos (Quijano, 1998). En este mismo sentido, las relaciones de dominación, explotación y conflicto, han estado históricamente asociadas a las distinciones raciales de la diferencia colonial. En consecuencia las luchas que se han gestado en este campo de ningún modo han ocasionado el pleno reconocimiento, por parte de las elites blancas, de la igualdad de los demás sectores.

En otras palabras, la colonialidad del poder ha hecho históricamente imposible una democratización real en estas naciones. Por ende, la historia latinoamericana está caracterizada precisamente por la parcialidad y la precariedad de los Estados-Nación, así como por la conflictividad inherente a sus sociedades.

Efectivamente, la independencia latinoamericana reconfiguró el control de las relaciones de poder en las antiguas unidades político-administrativas hispánicas. No obstante, este reacomodo mantuvo y ratificó la colonialidad del poder, esta vez de la mano de los sectores blancos e ilustrados de la sociedad. Aunque en cada una de las distintas sociedades, eran una reducida minoría del total de la población, los sectores blancos ejercían la dominación y la explotación de las mayorías de indígenas, afrodescendientes y mestizos que habitaban las nacientes repúblicas. Estos grupos mayoritarios no tuvieron acceso al control de los medios de producción, fueron impelidos de representar sus subjetividades (religiosas, idiomáticas, artísticas, etc.) y al mismo tiempo quedaron imposibilitados para participar en la dirección de la autoridad colectiva. Como lo ha hecho notar con claridad Aníbal Quijano, América Latina ha estado históricamente conformada por Estados independientes pero con sociedades coloniales ${ }^{14}$.

Al ser la colonialidad del poder la base de la estructuración de la sociedad en América Latina, la precariedad y parcialidad de la conformación de los Estados-Nación implica, a su vez, la difícil sostenibilidad de las identidades nacionales. En este marco, el ordenamiento político, administrativo y militar de las repúblicas latinoamericanas, dirigido por las elites blancas estructuró, en el mismo movimiento histórico, la configuración de imaginarios sociales y memorias históricas que instituyeran la identidad nacional, al tiempo que ocultaban las jerarquías internas configuradas por la colonialidad del poder (Quintero, 2009).

En consecuencia, este particularismo de las sociedades latinoamericanas, produjo cuatro trayectorias históricas y sedimentos ideológicos disímiles en las formaciones nacionales latinoamericanas (Quijano, 2000a).

Primeramente, en naciones como México, Bolivia y Cuba, a través de revoluciones radícales, se gestó un proceso inconcluso pero real, de democratización y de descolonización mediante una política identitaria asimilacionista para con las mayorías étnicas. En segundo lugar, en la mayoría de los países del cono sur, como en Chile, Uruguay y Argentina, se produjo un proceso efectivo, pero incompleto, de homogeneización racial y cultural de la población a partir de

\footnotetext{
${ }^{14} \mathrm{Al}$ igual que lo hiciéramos en una nota anterior para la noción de colonialismo. Es necesario en este punto establecer una diferenciación entre la idea de colonialidad y la noción de colonialismo interno. Entre finales de los sesenta y principios de los setenta, principalmente Pablo González Casanova (1969) y Rodolfo Stavenhagen (1969), introdujeron la categoría analítica de colonialismo interno para caracterizar la estructuración de las relaciones sociales en los países del Tercer Mundo. Teniendo como marco analítico el capitalismo y anclada en el binomio desarrollo/subdesarrollo, la noción de colonialismo interno exploraba las relaciones de dominación ejercidas por la burguesía y el latifundismo criollo sobre las poblaciones periféricas o subdesarrolladas dentro del mismo Estado-Nación. Sí bien la categoría de colonialismo interno antecede e incluso influye a la noción de colonialidad del poder, esta última se edifica en un marco analítico de mayor extensión y complejidad. Hace pocos años González Casanova (2006) intentó una reconceptualización del colonialismo interno defendiendo la vigencia de esta categoría, mientras que muy recientemente Stavenhagen (2009) ha cuestionado el lado añoso e irregular de su propio concepto, decantándose por el uso de la noción de colonialidad del poder.
} 
políticas de exterminio masivo de las masas indígenas y afrodescendientes, acompañadas de enérgicas políticas de favorecimiento de la inmigración europea. En tercer lugar, en Perú, Ecuador, Guatemala y Nicaragua, a través de políticas de exterminio se desarrolló un proceso absolutamente frustrado de homogeneización de la población indígena y afrodescendiente, que ha desembocado en violentos conflictos políticos e identitarios, principalmente entre criollos e indígenas. Finalmente, en países como Brasil, Colombia, Panamá y Venezuela, donde la población no blanca constituye una considerable mayoría, se ejecutó un proceso de enmascaramiento de las jerarquías raciales, a través del mito de la democracia racial que logró invisibilizar los conflictos étnico/raciales, aún cuando ellos forman parte de la cotidianidad de la vida social en estas naciones.

\section{Bibliografía}

CORONIL, F. (2000): "Naturaleza del Poscolonialismo: Del eurocentrismo al globocentrismo", en E. Lander (Comp.) La Colonialidad del Saber: Eurocentrismo y ciencias sociales. Perspectivas latinoamericanas. CLACSO, Buenos Aires (págs. 87-111).

DUSSEL, E. (2000): "Europa, Modernidad y Eurocentrismo", en E. Lander (Comp.) La Colonialidad del Saber: Eurocentrismo y ciencias sociales. Perspectivas latinoamericanas. CLACSO, Buenos Aires (págs. 41-53)

(1994): El Encubrimiento del Otro. Hacia el origen del mito de la modernidad. Ediciones Abya-Yala, Quito.

ESCOBAR, A. (2005): Más Allá del Tercer Mundo. Globalización y diferencia. Universidad del Cauca / ICANH, Bogotá.

GONZÁLEZ CASANOVA, P. (2006): "Colonialismo Interno (una redefinición)”, en A. Boron, J. Amadeo y S. González (Comps.) La Teoría Marxista Hoy: Problemas y perspectivas. CLACSO, Buenos Aires (págs. 409-434).

(1969): Sociología de la Explotación. Siglo XXI Editores, México.

LANDER, E. (1997): "Modernidad, Colonialidad, Postmodernidad", Revista Venezolana de Economía y Ciencias Sociales, Vol. 3, No. 4, Caracas (págs. 11-28).

LUGONES, M. (2008): “Colonialidad y Género", Tabula Rasa, Vol. 5, No. 9, Bogotá (págs. 73-101).

MARIÁTEGUI, J. C. (1928[1979]): Siete Ensayos de Interpretación de la Realidad Peruana. Biblioteca Ayacucho, Caracas.

MARX, K. (1867[1975]): El Capital. Tomo I, Vols. 1, 2 y 3. Siglo XXI Editores, México.

MEILLASSOUX, C. (1977): Mujeres, Graneros y Capitales. Siglo XXI Editores, México.

MIGNOLO, W. (2003): Historias Locales / Diseños Globales: Colonialidad, conocimientos subalternos y pensamiento fronterizo. Ediciones Akal, Madrid.

PALERMO, Z. (2006): "Inscripción de la Crítica de Género en Procesos de Descolonización", en Z. Palermo (coord.) Cuerpo(s) de Mujer: Representación simbólica y crítica cultural. Universidad Nacional de Salta / Ferreira Editor, Córdoba (págs. 237-265).

(2005): Desde la Otra Orilla: Pensamiento crítico y políticas culturales en América Latina. Alción Editora, Córdoba.

QUIJANO, A. (2009): "Colonialidad del Poder y Des/colonialidad del Poder", Conferencia dictada en el XXVII Congreso de la Asociación Latinoamericana de Sociología, Buenos Aires (págs. 1-15).

(2007a): "Don Quijote y los Molinos de Viento en América Latina", en O. Kozlarek (Coord.) De la Teoría Crítica a Una Crítica Plural de la Modernidad. Universidad Michoacana de San Nicolás de Hidalgo / Editorial Biblos, Buenos Aires (págs. 123146).

(2007b): “Colonialidad el Poder y Clasificación Social”, en S. Castro-Gómez y R. Grosfoguel (Eds.) El Giro Decolonial: Reflexiones para una diversidad epistémica más 
allá del capitalismo global. Pontificia Universidad Javeriana / Siglo del Hombre Editores, Bogotá (págs. 93-126).

(2004): "El Laberinto de América Latina: ¿Hay otras salidas?”, Revista Venezolana de Economía y Ciencias Sociales, Vol. 10, No. 1, Caracas (págs. 75-97).

(2002): "El Regreso del Futuro y las Cuestiones de Conocimiento", en C. Walsh, F. Schiwy y S. Castro-Gómez (Eds.) Indisciplinar las Ciencias Sociales: Geopolíticas del conocimiento y colonialidad del poder. Perspectivas desde lo andino. Universidad Andina Simón Bolívar / Ediciones Abya-Yala, Quito (págs. 45-60).

(2001a): "Colonialidad del Poder, Globalización y Democracia", en VVAA Tendencias Básicas de Nuestra Época: Globalización y democracia. Instituto de Estudios Diplomáticos e Internacionales Pedro Gual, Caracas (págs. 25-61). (2001b): "La Colonialidad y la Cuestión del Poder", texto inédito, Lima (págs. 1-21). (2000a): "Colonialidad del Poder, Eurocentrismo y América Latina", en E. Lander (Comp.) La Colonialidad del Saber: Eurocentrismo y ciencias sociales. Perspectivas latinoamericanas. CLACSO, Buenos Aires (págs. 201-246). (2000b): "El Fantasma del Desarrollo en América Latina", Revista Venezolana de Economía y Ciencias sociales, Vol. 6, No. 2, Caracas (págs. 73-90). (2000c): “¿Qué Tal Raza!”, Revista Venezolana de Economía y Ciencias sociales, Vol. 6, No. 1, Caracas (págs. 37-45).

(1998): "La Colonialidad del Poder y la Experiencia Cultural Latinoamericana", en R. Briceño-León y H. Sonntag (Eds.) Pueblo, Época y Desarrollo: La sociología de América Latina. Universidad Central de Venezuela / Editorial Nueva Sociedad, Caracas (págs. 27-38).

(1993): "Raza, Etnia y Nación en Mariátegui: Cuestiones abiertas", en R. Forgues (Ed.) José Carlos Mariátegui y Europa. La otra cara del descubrimiento. Editorial Amauta, Lima (págs. 166-187).

(1992): "Colonialidad y Modernidad/Racionalidad", en H. Bonilla (Comp.) Los Conquistados: 1492 y la población indígena de las Américas. FLACSO / Ediciones Libri Mundi, Quito (págs. 437-449).

(1990): "Modernidad, Identidad y Utopía en América Latina", en E. Lander (Ed.) Modernidad y Universalismo. Universidad Central de Venezuela / Editorial Nueva Sociedad, Caracas (págs. 27-42).

(1989): "La Nueva Heterogeneidad Estructural de América Latina", en H. Sonntag (Ed.) ¿Nuevos Temas, Nuevos Contenidos?: Las ciencias sociales de América Latina y el Caribe ante el nuevo siglo UNESCO / Editorial Nueva Sociedad, Caracas (págs. 2951).

(1979): "Prólogo. José Carlos Mariátegui: Reencuentro y debate", en J. C. Mariátegui Siete Ensayos de Interpretación de la Realidad Peruana. Biblioteca Ayacucho, Caracas (págs. IX-XCI).

(1975): "Cultura y Dominación (notas sobre el problema de la participación cultural)", en A. Chacón (Ed.) Cultura y Dependencia. Monte Ávila Editores, Caracas (págs. 85-113).

QUIJANO, A. y WALLERSTEIN, I. (1992): "Americanity as a Concept, or the Americas in the Modern World-System", International Social Science Journal, Vol. 134, No. 1, Paris (págs. 549-557).

QUINTERO, P. (2009): "La Colonialidad del Poder y el Mito de la Democracia Racial en Venezuela", en M. Ayala y P. Quintero (comps.) Diez Años de Revolución en Venezuela: Historia, balance y perspectivas. Editorial Maipue, Ituzaingó (págs. 203238).

STAVENHAGEN, R. (2009): "Repensar América Latina desde la Subalternidad: El desafío de Abya-Yala", Conferencia dictada en Secretaría Ejecutiva del Consejo Latinoamericano de Ciencias Sociales, Buenos Aires (1-14).

(1969): Las Clases Sociales en las Sociedades Agrarias. Siglo XXI Editores, México. 
TOMICH, D. (2004): Through the Prism Slavery: Labor, capital and world economy. Rowman Littlefield Publishers, Lanham.

WALLERSTEIN, I. (1990): "Análisis de los Sistemas Mundiales", en A. Giddens y J. Turner (Comps.) La Teoría Social Hoy. Alianza Editorial, Madrid (págs. 398-417).

WRIGHT MILLS, C. (1961): La Imaginación Sociológica. Fondo de Cultura Económica, México. 